\title{
PRE-OPERATIVE CORRECTION IN ADOLESCENT IDIOPATHIC SCOLIOSIS
}

\author{
M. A. EDGAR, R. H. CHAPMAN, M. M. S. GLASGOW
}

From the Scoliosis Unit, Royal National Orthopaedic Hospital, London

\begin{abstract}
One hundred and sixty-seven patients with adolescent idiopathic scoliosis were allocated prospectively to one of three different groups for correction before undergoing posterior spinal fusion and Harrington instrumentation. In Group 1 single curves were corrected by a Risser turnbuckle plaster jacket and double curves by halo-pelvic traction. In Group 2 patients performed Cotrel dynamic traction for three weeks and this was followed by correction in a plaster cast. In Group 3 patients were given Cotrel dynamic traction for one week only and the operation was performed without a plaster cast. There was no significant difference in the overall correction achieved among the patients in the three groups except that double curves corrected slightly better in Group 2. The correction achieved by Cotrel dynamic traction after three weeks was not significantly different from that obtained at $\mathbf{4 8}$ hours. An anteroposterior radiograph of the spine taken during Cotrel dynamic traction was a valuable guide to the mobility of the curve and is preferable to radiographs of the patient bending laterally, particularly with respect to curves over 70 degrees. The paper concludes that correction before operation is not required routinely in adolescent idiopathic curves unless the deformity is a severe and rigid one in which case a radiograph during Cotrel traction is a useful assessment.
\end{abstract}

During the post-war period a number of methods were developed to correct scoliosis before posterior spinal fusion. Corrective plaster jackets included the Risser turnbuckle cast (Risser et al. 1953), the Risser localiser cast (Risser 1955; Moe 1972), the Cotrel E.D.F. (élongation, dérotation, flexion) cast (Cotrel and Morel 1964), and the Stagnara distraction jacket (Moe et al. 1978). The development of the halo (Dewald and Ray 1970; Perry 1972), allowed skeletal traction-either halofemoral, halo-tibial (Daymond 1977) or halo-pelvic (O'Brien, Yau and Hodgson 1973) - to be used. In 1968 Cotrel and D'Amore described a system of dynamic halter traction and this has been advocated as an effective and simple means of correction before operation (Hensinger and MacEwen 1974; Cotrel 1975).

With the introduction of Harrington instrumentation it became possible to correct scoliosis during the operation. As a result the need for prior correction has been questioned and, in particular, doubt has been cast on the value of Cotrel traction (Nachemson and Nordwall 1976).

This prospective study has been carried out to assess the value of Cotrel dynamic traction in relation to the previously used methods of pre-operative correction and to investigate the general role of such correction in patients with adolescent idiopathic scoliosis.

\section{MATERIALS AND METHODS}

One hundred and sixty-seven patients with adolescent idiopathic scoliosis admitted to the Royal National Orthopaedic Hospital, Stanmore, for spinal fusion between 1975 and 1978 were studied. They were allocated prospectively to one of three groups for correction of their scoliosis before treatment by posterior spinal fusion with Harrington instrumentation.

Group 1. Patients with single curves underwent correction by a Risser turnbuckle cast using the method set out by Risser et al. (1953). Double curves were corrected by means of halo-pelvic traction following a standard procedure described by Ransford and Manning (1975) and Edgar (1979). The study of these patients formed a base line for the other two groups as the method of correction followed the routine procedure used at the Royal National Orthopaedic Hospital during the period up to 1975. An anteroposterior radiograph of the correction was taken.

Group 2. Patients with single and double curves carried out intermittent Cotrel dynamic traction following his standard technique apart from minor modifications. The cross-pelvic straps were replaced by a lumbosacral corset which was found to be more comfortable. Patients performed the exercises as a class, the dynamic traction

M. A. Edgar, MChir, FRCS, Consultant Orthopaedic Surgeon

R. H. Chapman, FRCS, Senior Registrar

M. M. S. Glasgow, FRCS, Senior Registrar

The Scoliosis Unit, Royal National Orthopaedic Hospital, Country Branch, Brockley Hill, Stanmore, Middlesex, England.

Requests for reprints should be sent to Mr M. A. Edgar.

(C) 1982 British Editorial Society of Bone and Joint Surgery 0301-620X/82/5122-0530\$2.00 
being carried out for 10 minutes each hour during the day. The force exerted by the patient was estimated using modified bathroom scales fixed to the bottom of the bed (Fig. 1). The webbing straps running down the bed from the pelvic corset were attached to lugs welded onto the footplate of the scales. The amount of correction of the scoliosis was measured from an anteroposterior spinal radiograph taken when the patient was performing maximum dynamic traction (Fig. 1); the amount of traction force exerted was recorded on the film.

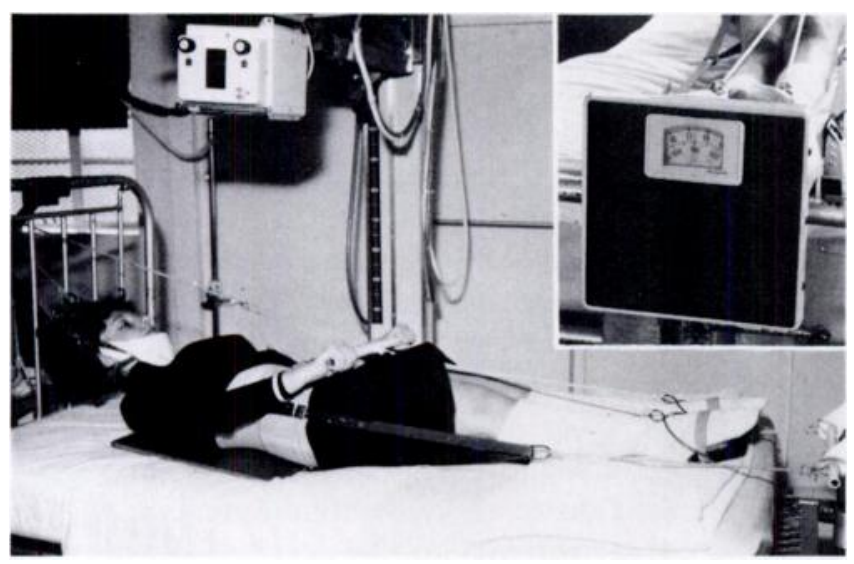

Fig. 1

Photograph of a patient performing Cotrel dynamic traction while a maximal dynamic traction radiograph is being taken. The inset shows the modified bathroom scales which are attached to the bottom of the bed and used for measurement of the traction force.

Radiographs in maximal dynamic traction were taken 14 and 21 days after commencing Cotrel traction. In addition, 13 patients had films in maximal dynamic traction taken at one to two days after starting Cotrel traction (the radiograph was taken as soon as it was felt that the patient had mastered the traction technique) and then at seven days and 14 days. As the findings in these 13 patients were consistent it was thought unnecessary to expose more patients to several irradiations.

Just before the operation a plaster body jacket of the Cotrel type (Cotrel and Morel 1964) was applied and a posterior window made in it for surgical access. A radiograph of the correction was then taken.

Group 3. Patients carried out a Cotrel dynamic traction programme as described for Group 2. A film of maximal dynamic traction was taken at seven days and surgery was then performed without a plaster body cast.

Preliminary assessment in all patients included an erect full-length anteroposterior and lateral radiograph of the spine. Spinal films with the patient supine and bending laterally were carried out routinely.

The operation consisted of a standard posterior spinal fusion with decortication of the posterior elements to the tips of the transverse processes and standard bilateral Moe fusion of the posterior facet joints. Autogenous cancellous bone chips were taken from the posterior ilium and were supplemented by bone from excised spinous processes. A solitary Harrington distraction rod was used.

When the wound had healed, 10 to 14 days after operation, a plaster body jacket with an abdominal window was applied. Anteroposterior and lateral radiographs of the spine with the patient erect were then taken before the patient was mobilised. Five months later the plaster cast was removed and a Milwaukee brace worn for a further five months. The final correction was judged from radiographs taken erect one year after operation.

\section{RESULTS}

The overall characteristics of the three groups of patients are set out in Table I.

Group 1. Of the 59 patients who entered this group, 50 were female. The average age was 15.2 years with a range of 12 to 21 years (standard deviation \pm 2.7 ). Fifty patients had a single scoliosis and nine a double curve. The average time in hospital before operation was four weeks.

Among the 50 single curves, 46 were in the thoracic region and four in the thoracolumbar region. The initial Cobb angle of the single curves was a mean 67.4 degrees. After correction in the Risser plaster cast the mean Cobb angle was reduced to 29.7 degrees (55.9 per cent correction). The radiograph taken after operation with the patient erect showed a mean Cobb angle of 33.7 degrees ( 50.0 per cent correction). The final film one year after operation showed a mean of 39.1 degrees $(42.0$ per cent correction). It can be seen that a mean 5.4 degrees were lost during the year after operation.

The double curves presented with an initial mean Cobb angle of 67.0 degrees for the upper curve and 61.9 degrees for the lower curve. After correction on halopelvic traction the radiograph showed a mean of 45.1 degrees for the upper curve ( 32.7 per cent correction) and a mean of 37.3 degrees for the lower curve (39.7 per cent correction). After operation the figures for the films taken with the patient erect were 46.0 degrees ( 31.3 per cent

Table I. Characteristics of the three groups of patients

\begin{tabular}{|c|c|c|c|c|c|c|c|c|}
\hline \multirow[b]{2}{*}{ Group } & \multirow{2}{*}{$\begin{array}{l}\text { Number of } \\
\text { patients }\end{array}$} & \multirow{2}{*}{$\begin{array}{c}\text { Mean age } \\
\text { (years) }\end{array}$} & \multirow{2}{*}{$\begin{array}{c}\text { Number of } \\
\text { female } \\
\text { patients }\end{array}$} & \multirow{2}{*}{$\begin{array}{c}\text { Number of } \\
\text { single curve } \\
\text { patients }\end{array}$} & \multirow{2}{*}{$\begin{array}{l}\text { Mean initial Cobb } \\
\text { angle of single } \\
\text { curves } \\
\text { (degrees) }\end{array}$} & \multirow{2}{*}{$\begin{array}{c}\text { Number of } \\
\text { double curve } \\
\text { patients }\end{array}$} & \multicolumn{2}{|c|}{$\begin{array}{l}\text { Mean initial Cobb angle of } \\
\text { double curves (degrees) }\end{array}$} \\
\hline & & & & & & & Upper curve & Lower curve \\
\hline 1 & 59 & 15.2 & 50 & 50 & 67.4 & 9 & 67.0 & 61.9 \\
\hline 2 & 57 & 14.6 & 48 & 42 & 66.4 & 15 & 70.1 & 61.8 \\
\hline 3 & 51 & 14.6 & 39 & 38 & 63.6 & 13 & 62.7 & 67.5 \\
\hline
\end{tabular}


correction) and 35.4 degrees (42.8 per cent correction) respectively. One year after operation the upper curve showed a mean angle of 50.0 degrees $(25.4$ per cent correction) and the lower curve 41.5 degrees (33.0 per cent correction). The mean loss during the year after operation was therefore 4.0 degrees for the upper curve and 6.1 degrees for the lower curve.

Group 2. Of the 57 patients who entered this group, 48 were female. The average age was 14.6 years with a range of 11 to 21 years (standard deviation \pm 1.8 ). Fortytwo patients had a single scoliosis and 15 had a double curve. The average time in hospital before operation was 3.5 weeks.

The single curves were located in the lower thoracic region in 37 patients and in the thoracolumbar region in five. The initial mean Cobb angle of the single curves was 66.4 degrees. The Cotrel maximal dynamic traction film before operation had a mean of 35.7 degrees (46.2 per cent correction). (Correlation of the correction obtained on maximal dynamic traction films taken after varying lengths of time on Cotrel traction is presented in a separate section below.) The film taken in the Cotrel cast just before operation showed a mean angle of 34.6 degrees (47.9 per cent correction). After operation the mean angle was 31.3 degrees (52.9 per cent correction). At one year the film showed a mean Cobb angle of 35.9 degrees (45.9 per cent correction). Therefore the mean angle loss during the year was 4.6 degrees.

The 15 double curves had initial mean angles for the upper and lower components of 70.1 degrees and 61.8 degrees respectively. The film of Cotrel maximal dynamic traction produced means of 42.8 degrees ( 38.9 per cent correction) and 35.0 degrees ( 43.4 per cent correction). In the Cotrel cast the mean angles were improved to 41.6 degrees ( 40.7 per cent correction) for the upper curve and 33.3 degrees (46.1 per cent correction) for the lower curve. After operation the mean angles were 39.4 degrees (43.8 per cent correction) and 29.3 degrees ( 52.6 per cent correction) for the upper and lower curves. A year later the mean Cobb angle was 42.7 degrees (39.1 per cent correction) and 37.5 degrees (39.3 per cent correction) respectively. Therefore over the year the upper curve had lost a mean 3.3 degrees and the lower curve a mean 8.2 degrees.
Group 3. Fifty-one patients were studied, 39 being female. The average age was 14.6 years, with a range of 11 to 21 years (standard deviation \pm 2.1 ). Thirty-eight of the patients had single curves; three curves were in the thoracolumbar region and 35 were in the lower thoracic spine. The mean time in hospital before operation was one week.

The mean initial Cobb angle of the single curves was 63.6 degrees. The film of maximal dynamic traction after one week of Cotrel traction showed a mean angle of 32.8 degrees (48.4 per cent correction). After operation the radiograph had a mean Cobb angle of 32.0 degrees (49.7 per cent correction). At one year the average single angle was 36.4 degrees (42.8 per cent correction). Therefore, a mean 4.4 degrees were lost over the year between operation and fusion.

There were 13 double curves in Group 3. The initial mean angle for the upper curves was 62.7 degrees and for the lower curves 67.5 degrees. Maximal dynamic traction reduced these angles to a mean of 40.7 degrees (35.1 per cent correction) for the upper component and 37.8 degrees (44.0 per cent correction) for the lower component. The mean angles after operation were 43.0 degrees (31.4 per cent correction) and 39.4 degrees ( 41.6 per cent correction) respectively. At one year the mean angles stood at 47.0 degrees (25.0 per cent correction) and 46.9 degrees (30.5 per cent correction). Therefore the mean loss over the year after the operation for the upper curves was 4.0 degrees and for the lower curves 7.5 degrees.

Correlation of single curve correction. The amount of correction achieved after the operation and that seen one year later correlates well among the three groups and statistically there is no significant difference (Table II). There is a consistent deterioration over the year after the operation in each group.

Figure 2 shows the correlation of the correction after the operation in the three groups according to the size of the initial angle. The smaller curves below 50 degrees tended to correct better in Group 1 whereas curves over 50 degrees fared slightly better in Group 2 and Group 3.

In Group 1 patients, although there was an impressive correction due to the Risser jacket, there was a mean four-degree loss shown between this film and the

Table II. Mean percentage correction of the single and double curves in the three groups at different stages

\begin{tabular}{|c|c|c|c|c|c|c|c|c|c|c|}
\hline \multirow[b]{3}{*}{ Group } & \multicolumn{5}{|c|}{ Single curves } & \multicolumn{5}{|c|}{ Double curves } \\
\hline & \multicolumn{4}{|c|}{ Mean correction (per cent) } & \multirow[b]{2}{*}{$\begin{array}{l}\text { Mean loss } \\
\text { (degrees) }\end{array}$} & \multicolumn{4}{|c|}{ Mean correction (per cent) } & \multirow[b]{2}{*}{$\begin{array}{c}\text { Mean loss } \\
\text { (degrees) }\end{array}$} \\
\hline & $\begin{array}{l}\text { Cotrel maximal } \\
\text { dynamic traction }\end{array}$ & $\begin{array}{c}\text { Before } \\
\text { operation }\end{array}$ & $\begin{array}{c}\text { After } \\
\text { operation }\end{array}$ & $\begin{array}{c}\text { One year } \\
\text { after } \\
\text { operation }\end{array}$ & & $\begin{array}{l}\text { Cotrel maximal } \\
\text { dynamic traction }\end{array}$ & $\begin{array}{c}\text { Before } \\
\text { operation }\end{array}$ & $\begin{array}{c}\text { After } \\
\text { operation }\end{array}$ & $\begin{array}{c}\text { One year } \\
\text { after } \\
\text { operation }\end{array}$ & \\
\hline 1 & - & 55.9 & 50.0 & 42.0 & 5.4 & - & 36.2 & 37.1 & 28.2 & 5.1 \\
\hline 2 & 46.2 & 47.9 & 52.9 & 45.9 & 4.6 & 41.2 & 43.4 & 48.2 & 39.2 & 5.8 \\
\hline 3 & 48.4 & - & 49.7 & 42.8 & 4.4 & 39.6 & - & 36.5 & 27.8 & 5.8 \\
\hline
\end{tabular}


radiograph taken after operation. By contrast, Group 2 and 3 patients showed a small improvement between films taken before and after operation.

Correlation of double curve correction. From Table II it can be seen that Group 2 patients, that is those treated with a corrective plaster cast, before the operation obtained about 10 per cent more correction. Halo-pelvic traction offered no advantage. The overall correction in double curves was about 10 per cent less than in single curves. The significance of these findings is limited by the small number of double curves studied.

Interpretation of correction after maximal dynamic traction (Groups 2 and 3). In order to determine whether Cotrel dynamic traction gradually increases the mobility or correctability of the curve, 13 patients in Group 2 had serial films taken during Cotrel maximal dynamic traction. The first radiograph was obtained as soon as the patient was able to perform the technique properly; this occurred between one and two days. Subsequent films were taken after seven and 14 days.

The mean initial correction was 41.4 per cent. The mean correction on the seventh day was 44.1 per cent and on the fourteenth day the mean percentage correction was 45.1 per cent. This represents a mean improvement of two degrees in two weeks which is not significant statistically.

Similarly, when the mean correction during the maximal dynamic traction at various periods before operation was correlated among all the 57 patients in Group 2 no significant difference was found. A combined study of Group 2 and 3 patients further supports this finding. The mean correction during maximal dynamic traction for patients with single curves who had a film in maximal dynamic traction taken on the first day was 47.0 per cent (Group 2). The mean correction for single curves on the film of maximal dynamic traction after one week was 48.5 per cent (Group 2 and 3 ) whereas the mean correction after three weeks in patients with single curves was 46 per cent (Group 2 patients).

The correction shown on the films taken during Cotrel maximal dynamic traction gave a close estimate of the amount of correction to be achieved at operation. The 80 patients with single curves in Groups 2 and 3 produced a mean maximal dynamic traction angle of 34.3 degrees (47.3 per cent correction). The film taken with the patient erect after the operation had a mean Cobb angle of 31.5 degrees ( 51.4 per cent correction) and the film taken one year after the operation had a mean angle of 36.1 degrees (44.5 per cent correction). Figure 3 shows how this correlation is consistent across the range of curves.

Providing that the Cotrel traction force was above 25 kilograms there was no correlation between the amount of force used and the percentage correction obtained.

Correlation of spinal radiographs of lateral bending and Cotrel maximal dynamic traction (Groups 2 and 3). The radiographs of lateral bending and Cotrel maximal dynamic traction were correlated to assess their respective values in predicting correction after operation. It would appear that the two techniques are equally valuable in curves below 70 degrees but that the radiograph in maximal dynamic traction is more valuable in assessing the mobility of the curves greater than 70 degrees.
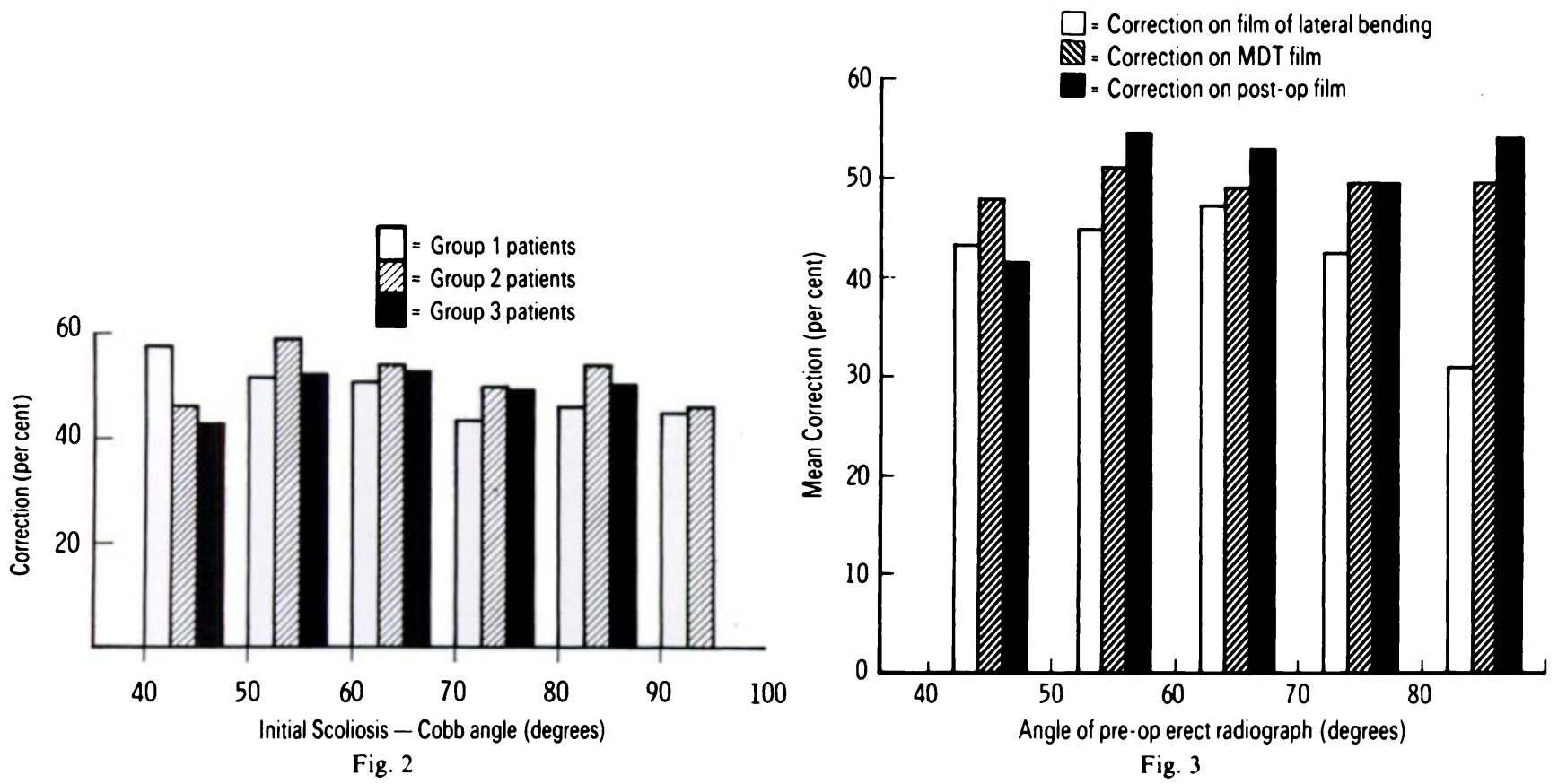

Figure 2-Histogram correlating the amount of correction after operation with the size of the initial Cobb angle. The angles are shown in 10 degree batches. Figure 3-Histogram in which the mean percentage correction achieved on the film of lateral bending, the film of maximal dynamic traction and the film of the patient erect after the operation are correlated in patients from Group 1 and Group 3 . The patients are subdivided according to the size of the initial Cobb angles of their curves. These are depicted in 10-degree groups. 


\section{ILLUSTRATIVE CASE REPORT}

A girl, aged 14 years (Group 2 patient), was admitted with an 82-degree lower right thoracic scoliosis of the adolescent idiopathic type (Fig. 4). Correction shown on the radiograph in lateral bending was to 58 degrees (Fig. 5). The film in maximal dynamic traction (with a force of 55 kilograms) demonstrated a correction to 37 degrees (Fig. 6). Before the operation the radiograph taken supine with the patient in a corrective localiser plaster cast showed the same angle. A standard posterior fusion and Harrington instrumentation was performed from T 4 to L 3 and this was followed by routine after-care. After the operation the Cobb angle was reduced to 36 degrees (Fig. 7). An erect radiograph taken one year later, when the spine was fused, showed a Cobb angle of 38 degrees (Fig. 8).

\section{DISCUSSION}

It is apparent from the findings before operation in Group 2 and 3 patients that Cotrel dynamic traction does not increase spinal mobility and hence produce a progressive correction of an idiopathic scoliosis. However, a radiograph taken during maximal dynamic traction is a useful measure of the innate mobility of the curve and a good guide to the eventual correction that can be obtained by distraction using Harrington instrumentation.

Cotrel et al. (1980) found that the correction on a film of maximal dynamic traction taken on the first day and then on the fourteenth day after starting Cotrel traction improved by seven per cent overall. The improvement was not significant for curves under 70 degrees but curves over 100 degrees achieved an additional correction of 14 per cent. The present study did not include such severe deformities but even with curves of 70 to 100 degrees significant increase in correction did not occur.

The film in Cotrel maximal dynamic traction taken before the operation would appear to give a better indication of the mobility of the curve than the film of lateral bending when the scoliosis is over 70 degrees. This observation supports those of Cotrel and D'Amore (1968). In addition, James (1976) found that films of the patient bending were not a reliable prediction of operative correction. A distraction force as opposed to a lateral-bending force is a more efficient means of

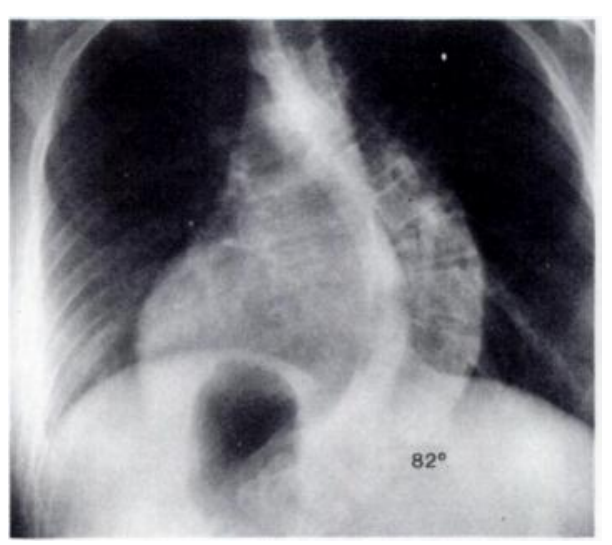

Fig. 4

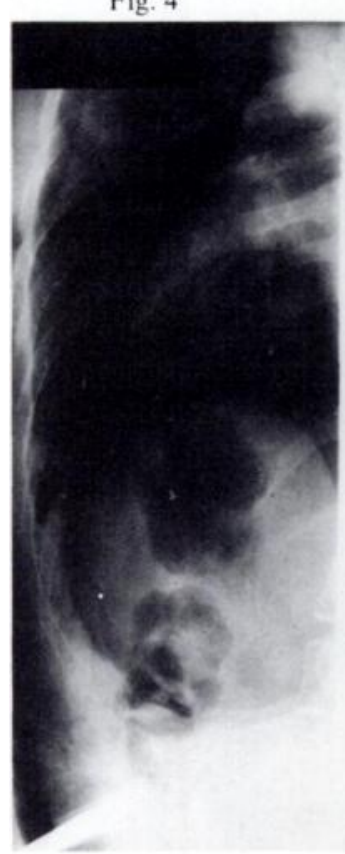

Fig. 7

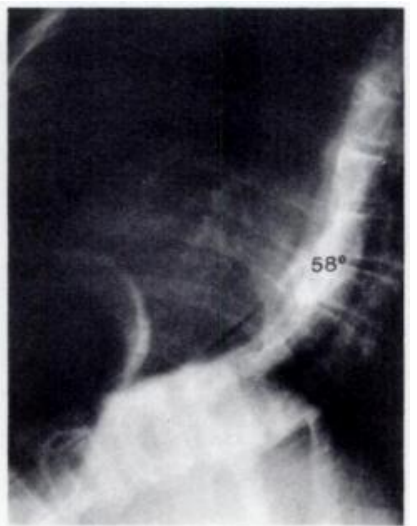

Fig. 5

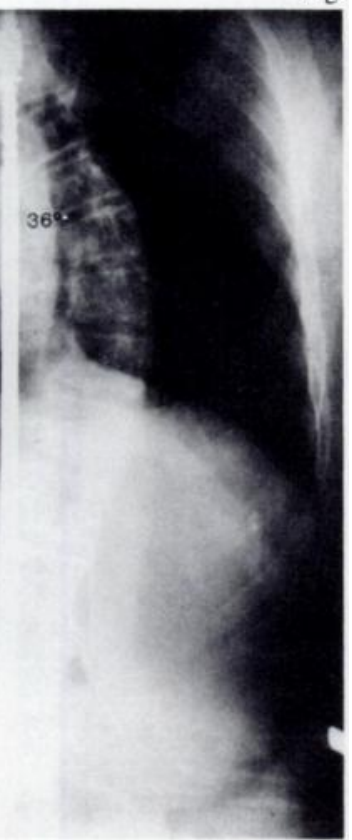

Case presentation (see text).

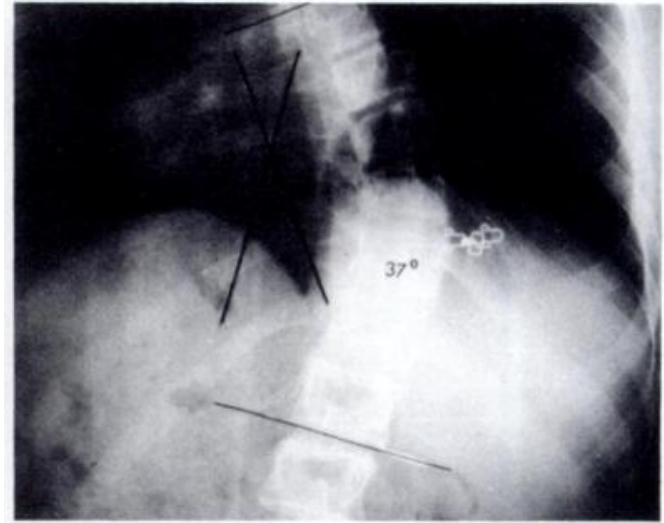

Fig. 6

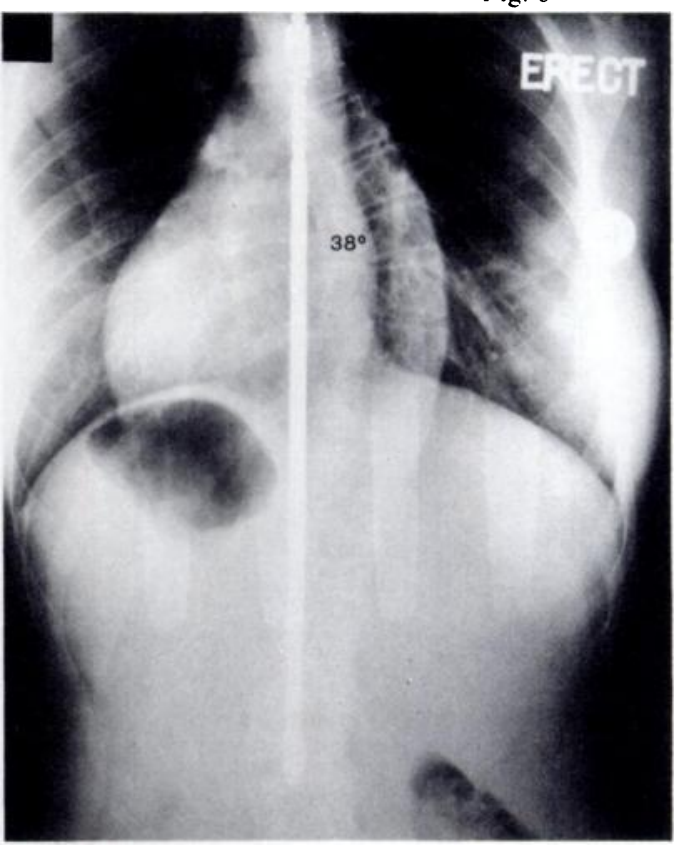

Fig. 8 
correcting scoliosis curves approaching 90 degrees. This would fit in with the greater efficiency of Cotrel traction in demonstrating the mobility of more severe deformities and it is in such cases that a demonstration of correctability is most valuable. The Cotrel method has the small but noteworthy advantage of less irradiation in that only one radiograph is required whereas two radiographs of lateral bending are needed if the mobility of the major and compensatory curves is to be judged.

The other interesting finding in this study concerns the minimal difference in the eventual correction between the three groups, especially among the single curves, despite the different methods of correction used prior to operation. This adds support to the belief that such prior correction is not a critical factor in idiopathic scoliosis. Nachemson and Nordwall (1976) found that Cotrel dynamic traction before operation provided no advantage when the correction after operation was compared with that obtained in patients who had not undergone any prior treatment. Therefore, a lengthy period in a plaster cast or in halo-pelvic traction before operation cannot be justified on the grounds of increased correction for idiopathic curves of up to 100 degrees.

In the severe or rigid curve, prior correction, whether by corrective cast or by skeletal traction, makes posterior spinal fusion technically easier and may add safety as well (Moe 1972). In such instances the films taken in Cotrel maximal dynamic traction are a useful test to detect the rigid deformity.

As a result of this study it is the current policy at the Royal National Orthopaedic Hospital for patients with idiopathic scoliosis to perform Cotrel dynamic traction for one to three days while routine blood tests and cardiorespiratory investigations are carried out. A film of the patient in maximal dynamic traction is then taken before operation in preference to films of lateral bending. Plaster correction or skeletal traction before operation is not used routinely.

\section{REFERENCES}

Cotrel Y. Traction in the treatment of vertebral deformity. J Bone Joint Surg [Br] 1975;57-B:269.

Cotrel Y, D'Amore M. Spinal traction in scoliosis. In: Zorab PA, ed. Proceedings of a second symposium on scoliosis. Edinburgh and London: E \& S Livingstone, 1968:37-43.

Cotrel Y, Morel G. La technique de l'E.D.F. dans la correction des scolioses. Rev Chir (Orthop) 1964;50:59-75.

Cotrel Y, Seringe R, Plais PY, Paluzak M. Spinal traction in scoliosis. In: Zorab PA, Siegler D, eds. Scoliosis 1979-based on the proceedings of the 6th symposium. London: Academic Press, 1980:241-61.

Daymond K. Use of halo-femoral traction in spinal surgery. J Bone Joint Surg [Br] 1977;59-B: 117.

Dewald RL, Ray RD. Skeletal traction for the treatment of severe scoliosis. J Bone Joint Surg [Am] 1970:52-A:233-8.

Edgar MA. Halopelvic distraction. In: Rob C, Smith R, eds. Operative surgery: Orthopaedics Part I. 3rd ed. London and Boston: Butterworths, 1979:383-8.

Hensinger RN, MacEwen GD. Evaluation of the Cotrel dynamic spine traction in the treatment of scoliosis. Orthop Rev 1974:3:27-34.

James JIP. Scoliosis. 2nd ed. Edinburgh: Churchill Livingstone, 1976:268.

Moe JH. Methods of correction and surgical techniques in scoliosis. Orthop Clin North Am 1972;3:17-48.

Moe JH, Winter RB, Bradford DS, Lonstein JE. Scoliosis and other spinal deformities. Philadelphia: WB Saunders, 1978:469.

Nachemson A, Nordwall A. The Cotrel dynamic spine traction: an ineffective method for pre-operative correction of scoliosis. J Bone Joint Surg $[\mathrm{Am}]$ 1976;58-A:158.

O'Brien JP, Yau ACMC, Hodgson AR. Halo-pelvic traction : a technique for severe spinal deformities. Clin Orthop 1973;93:179-90.

Perry J. The halo in spinal abnormalities. Orthop Clin North Am 1972;3:69-80.

Ransford AO, Manning CWSF. Complications of halo-pelvic distraction of scoliosis. J Bone Joint Surg [Br] 1975:57-B:131-7.

Risser JC. Scoliosis: the application of body casts for the correction of scoliosis. Am Acad Orthop Surg Instr Course Lect 1955;12:255-9.

Risser JC, Lauder CH, Norquist DM, Craig WA. Three types of body casts. Am Acad Orthop Surg Instr Course Lect 1953;10:131-42. 